\title{
Interpolating Socioeconomic Data for the Analysis of Deforestation: A Comparison of Methods
}

\author{
Michelle Farfán, Jean François Mas, Laura Osorio \\ Centro de Investigaciones en Geografía Ambiental, Universidad Nacional Autónoma de México, Morelia, Mexico \\ Email: farfanmichel@gmail.com
}

Received June 8, 2012; revised July 8, 2012; accepted August 2, 2012

\begin{abstract}
This study compares local-level socioeconomic variables interpolated with three different methods: 1) Thiessen polygons, 2) Inverse distance weighting, and 3) Areas of influence based on cost of distance. The main objective was to determine the interpolation technique capable of generating the most efficient variable to explain the distribution of deforestation through two statistical approaches: generalized linear models and hierarchical partition. The study was conducted in two regions of western Mexico: Coyuquilla River watershed, and the Sierra de Manantlan Biosphere Reserve (SMBR). For SMBR it was found that the Thiessen polygons and areas of influence were the techniques that interpolated variables with greatest explanatory power for the deforestation process, in Coyuquilla it was inverse distance weighting. These differences are related to the distribution and the spatial correlation of the values of the variables.
\end{abstract}

Keywords: Interpolation; Socioeconomic Variables; Deforestation; Hierarchical Partition

\section{Introduction}

Land-use/land-cover changes (LULCC) have become a central question to be addressed in recent years. Vitousek [1] and Agarwal et al. [2] state that the present level of LULCC constitutes - along with increasing levels of atmospheric carbon dioxide and variations in the global nitrogen cycle - the most evident and perceptible of global changes. Deforestation is known as one of the most important elements of LULCC. According to recent assessments, each year, on average, about 630,000 ha of temperate and tropical forests are cleared, accumulating a total loss of $50 \%$ of the original coverage in the last 20 years in Mexico [3]. The Global Forest Resource Assessment [4] ranks in 4th place the deforestation process in Mexico with an annual loss of 395,000 ha per year from 2000 to 2005 . The study of the factors that drive deforestation processes involves not only biophysical but also socioeconomic ones. However, in relation to the second, it is not straightforward to determine which have a greater impact on the processes of change. Some studies consider the demographic aspects as an important cause [5], nevertheless it has also been shown that population growth is not the main cause of deforestation $[6,7]$. It is rather a process that depends on a complex combination of socioeconomic and biophysical factors involving the interaction between humans and the environment [8]. In practice, the inclusion of socioeconomic data in deforestation studies consists in using databases gener- ated through surveys, which present the data arranged by a specific political-administrative demarcation (state or municipality). Nevertheless, the spatial representation of such units may not reflect their context, as it assumes that they are homogeneous areas to which an average value is assigned. It is therefore advantageous to manage information by locality, in order to express a greater degree of heterogeneity within each political-administrative demarcation-from where emerges the challenge of spatializing point data by means of some interpolation techniques. Geographical information systems (GIS) provide tools to fulfill such task by estimating the values of an environmental variable at unsampled sites using point data from observations within the same region. These methods have been widely used in other environmental matters like soil mapping $[9,10]$ and climatic data [11]. They have also been applied to ecological studies such as the prediction of forest volume [12] and the characterization of the spatial structure of vegetation communities [13].

\section{Methods}

\subsection{Location of Study Areas}

Two study areas were selected: 1) the Sierra de Manantlan Biosphere Reserve (SMBR) and its area of influence with $4577 \mathrm{~km}^{2}$ in Jalisco; and 2) the Coyuquilla River watershed, Guerrero, comprising an area of $637 \mathrm{~km}^{2}$ (Figure 1). 


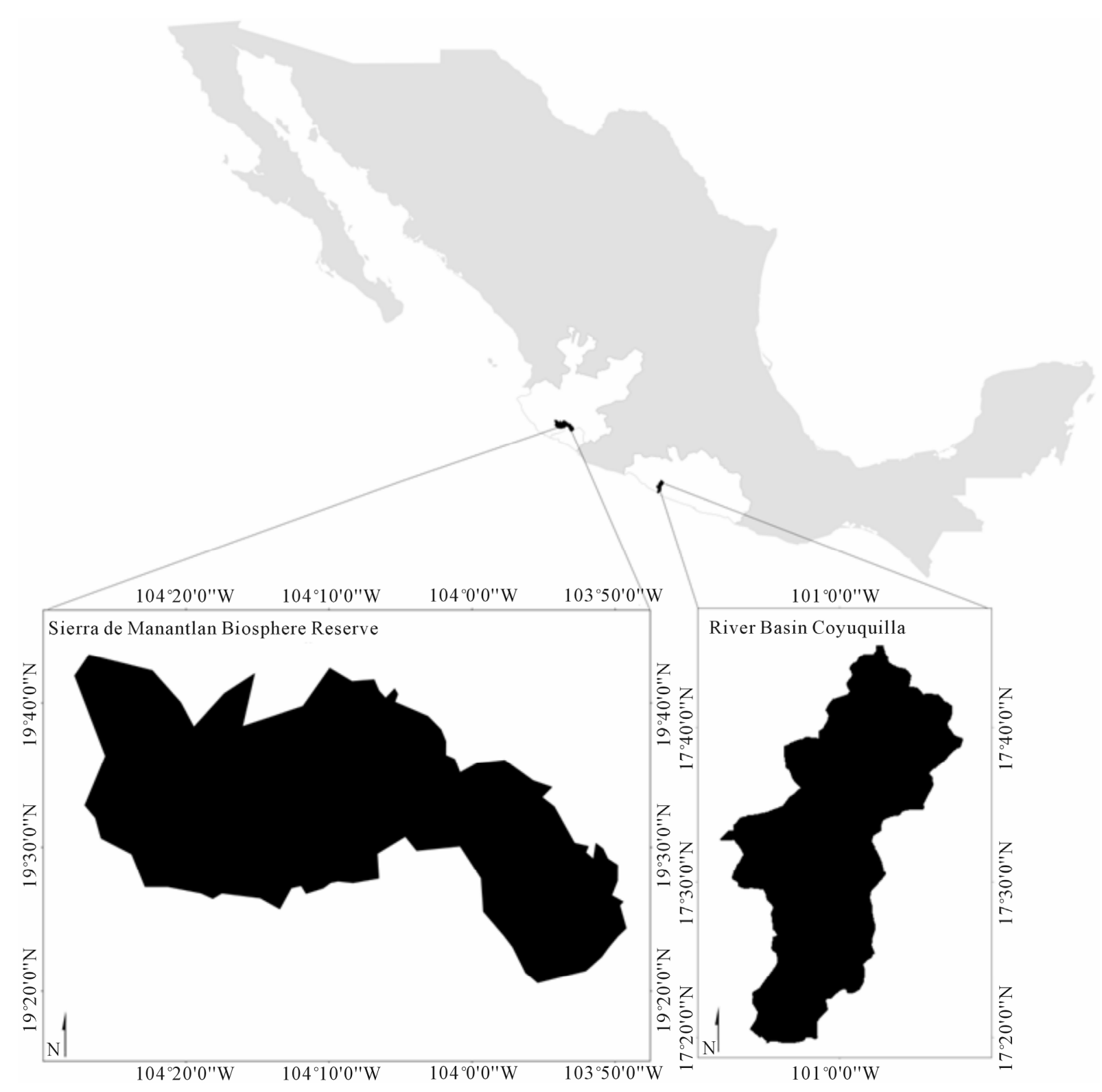

Figure 1. Location of study areas in Mexico.

\subsection{Material}

For the SMBR, land-use/land-cover (LULC) data for the year 1970 was obtained from a 1:50,000 scale map produced by the Instituto Nacional de Geografía, Estadística e Informática (INEGI, Mexico's official mapping agency). This was updated using SPOT images from December 2000 and December 2004. For the Coyuquilla River watershed, Landsat TM images dated February 1986 and May 2000 were used. In both cases, LULC maps were updated by the visual interdependent interpretation procedure $[14,15]$. This technique consists first in interpreting the image for the first date, and then modifying it based upon the image for the second date, therefore producing consistent change data.
The obtained data were used to produce binary maps defining conserved/deforested areas for the aforementioned periods. Random points were then sampled out of each binary map, 40,000 for SMBR and 19,000 for Coyuquilla. Roads maps (scale 1:250,000) and 90-meter resolution digital elevation models (DEM), both from INEGI, were used to generate the friction maps, basic input for the area of influence interpolation technique.

The interpolated socioeconomic variables were obtained from the Consejo Nacional de Población (National Population Council, CONAPO, 2000) at the locality level for the two regions. This information was integrated into a GIS database (ArcGIS version 9.3 and DINAMICA EGO version 1.6) in which the three interpolation tech- 
niques were carried out. Statistical analyses were made with R [16].

\subsection{Interpolation Techniques}

Correlation between the 13 socioeconomic variables from CONAPO (2000) was assessed with the Spearman coefficient, a non-parametric measure of statistical dependence. Variables with a correlation value equal to or greater than 0.7 were discarded. Then, the variables selected were spatially interpolated using three methods that are briefly described below. The first method used was Thiessen polygons or Voronoi diagrams. It is based on the Euclidean distance, which divides a region in a way that is totally determined by the configuration of the data points, with one polygon per observation. If the data lie on a regular square grid, then the Thiessen polygons are all equal, but if the data are irregularly spaced, then an irregular lattice of polygons results (see Figure 2(b)). Each polygon encloses the area closest to the central location in relation to the distance that keeps with the others to form their boundaries [17]. The entire polygon area receives the value of the attribute of the central point.

The second method is the inverse distance weighting

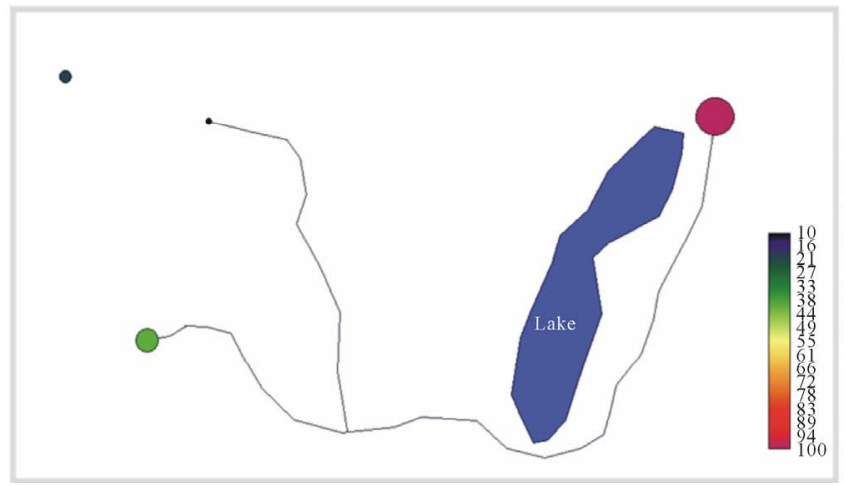

(a)

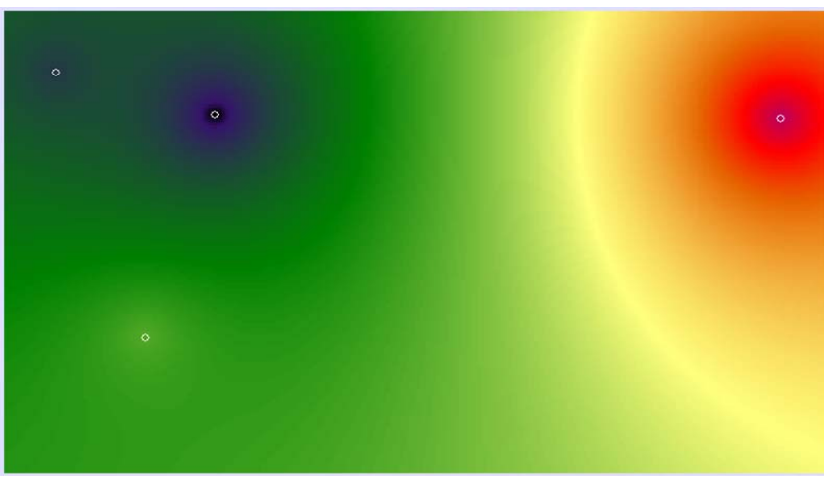

(c)
(IDW), which combines the idea of proximity espoused by the Thiessen polygons with the gradual change of the trend surface. The assumption is that the value of an attribute $\mathrm{z}$ at some unvisited point is a distance-weighted average of data points occurring within a neighborhood surrounding the unvisited point [18]. Sampled points closer to the unsampled point are more similar to it than those further away in their values [19]. For this study, IDW method was based on 20 and 12 neighboring points for SMBR and Coyuquilla, respectively.

Finally, we generated areas of influence around each locality from Thiessen-like polygons based on friction maps. This is a matrix of cells defining the energy cost for crossing each cell. In this study, the land use map in combination with roads and slope were used as inputs to calculate it. Each area of influence encloses the area closest to the central location in terms of travel time (Figure 2(d)).

\subsection{Statistical Comparison of Interpolation Procedure}

The performance of each interpolation technique, alone and in combination, was assessed through generalized linear models (GLM), which allow us to develop relationships

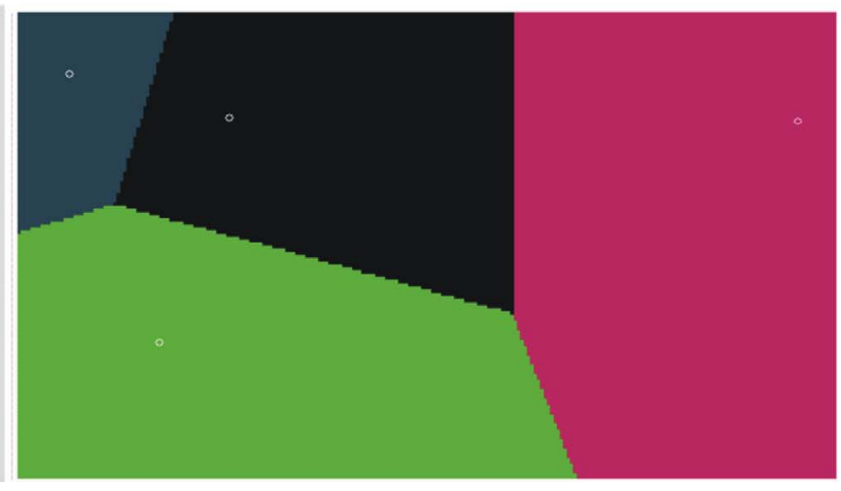

(b)

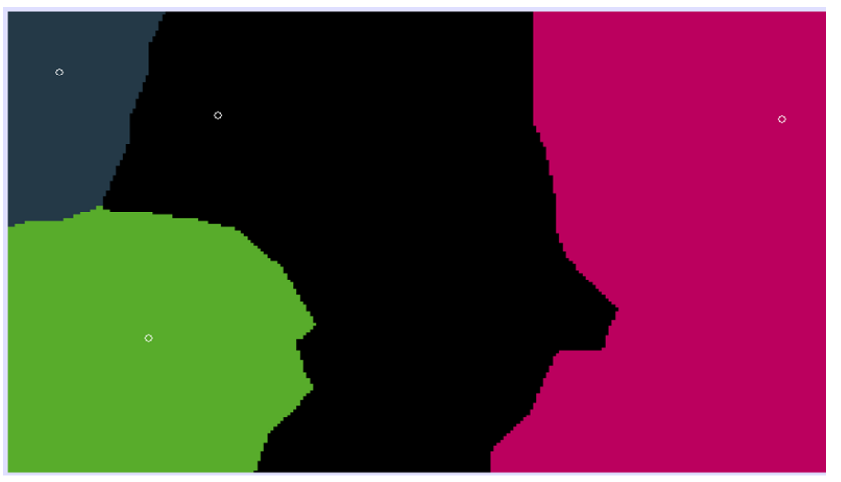

(d)

Figure 2. Hypothetical interpolation case of four locations. (a) With different attribute values, $z$, connected by two stretches of road and separated by a lake (barrier) using: Thiessen polygons (b); inverse distance weighted (c) and area of influence (d). Only the last technique takes into account the road and the lake. 
between the presence/absence of deforestation process and the interpolated variables.

The logistic relation was used since the dependent variable is binary. The statistical support of the GLM is that when the variance is not constant, it is possible to identify the contribution of one or more variables to explain the studied phenomenon. The resulting models were evaluated using the Akaike information criterion (AIC). This criterion incorporates the balance between statistical bias and variance in the factors that are added in the model and provides a comparison directly among themselves [20]. Models were fitted by a step-wise procedure and the relative contribution of each variable was assessed by its significance and the difference of AIC (DAIC) resulting when leaving out the variable from the model.

In addition, hierarchical partitioning (HP) was implemented, a protocol in which all possible models in a multiple regression setting are jointly considered to attempt to identify the most likely causal factors. It involves the calculation of the incremental "improvement" (i.e. increased goodness-of-fit) in models by the addition of a given variable $U$, and these are averaged over all combinations in which $U$ occurs to provide a measure of the effects of the independent variables [21]. The independent impact of variable $U$ is estimated by comparing the goodness-of-fit of all possible models involving U. In HP all such comparisons are made and averaged across independent variables and combinations of them in a consistent framework. For each independent variable, "explanatory" power is segregated into independent effects, I, and effects caused jointly with other variables, J $[22,23]$. The contribution to the total explained variance of a model of a predictor in conjunction with all others is found by subtracting the total variance explained by a predictor independently. This statistical approach [24] provides a measure of the explanatory power of multiple independent variables because it is not affected by multi-colinearity [25]. MacNally [26] suggests that those factors identified as influential both in regression models and HP are the causal variables among the ones with predictive power. Finally, the Moran index was calculated to assess the spatial autocorrelation of the variables analyzed.

\section{Results}

\subsection{Selection of the Interpolated Variables}

According to the Spearman correlation test, among the 13 socioeconomic variables from CONAPO (2000) only four were found to be not correlated for SMBR and five for Coyuquilla (Table 1).

The selected variables were interpolated through Thiessen polygons, IDW and areas of influence (Figures 3 and 4), and used in the GLM and HP.

\subsection{Comparison of Interpolation Techniques}

Table 2 shows the final GLM models for both study areas with the variables ranked according to the contribution of each variable to the model (DAIC). In general terms, it can be observed that the results of the final GLM model do not produce a consistent way of selecting an interpolation method since it offers a combined selection of mixed techniques. Instead, it was found that, for Coyuquilla as well as SMBR, the variable which exhibits the main contribution was the marginalization index, interpolated with the IDW technique and by Thiessen polygons, respectively.

On the other hand the HP results show that for the SMBR the interpolation techniques based on Thiessen polygons and areas of influence are able to spatially express the variables with greater independent explanatory power (I) for the deforestation process (see Table 3). Less important was the IDW technique. It is also possible to observe that the index of marginalization has the highest independent contribution, and in this respect agrees with GLM results. For Coyuquilla, the IDW was

Table 1. Socioeconomic independent variables considered for each study area. The symbol + indicates those variables that were interpolated by 3 methods (Thiessen polygons, IDW and area of influence).

\begin{tabular}{|c|c|c|c|}
\hline \multirow{2}{*}{ Socioeconomic variables } & \multicolumn{3}{|c|}{ Study area } \\
\hline & SMBR & Coyuquilla & Code \\
\hline Total population 2000 & & + & $\mathrm{TP}$ \\
\hline$\%$ of occupants in houses without sewage or toilet & + & + & WS \\
\hline$\%$ of occupants in homes without running water & & + & WW \\
\hline$\%$ of occupants in houses with earthen floor & + & + & $\mathrm{EF}$ \\
\hline$\%$ of employed people with an income up to 2 minimum wages & + & & MW \\
\hline Marginalization index & + & + & MI \\
\hline
\end{tabular}




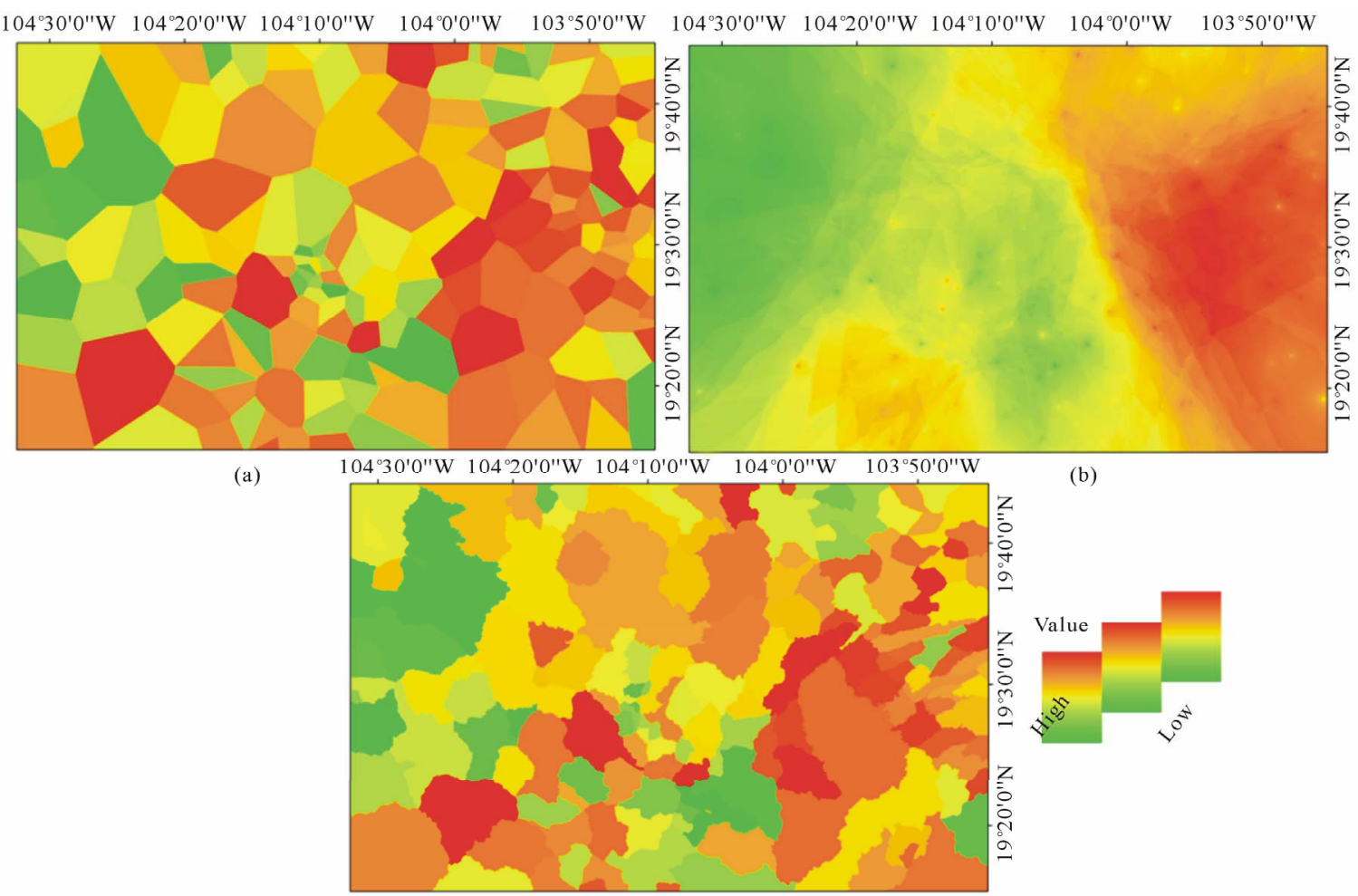

(c)

Figure 3. Interpolation of \% of employed people with an income up to 2 minimum wages (MW) with, Thiessen polygons (a), IDW (b) and areas of influence (c) for SMBR.

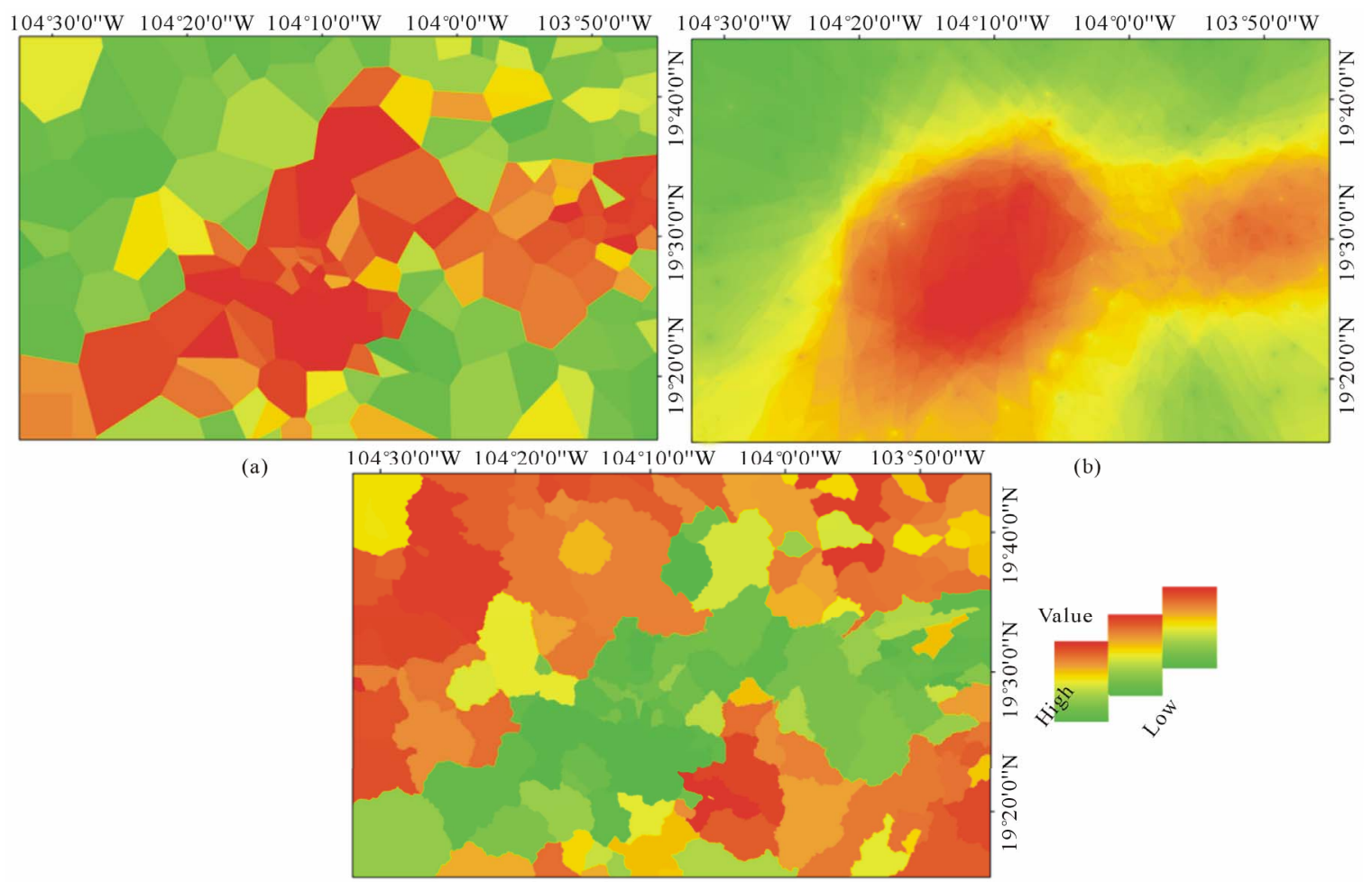

(c)

Figure 4. Interpolation of \% of occupants in houses with earthen floor (EF) with, Thiessen polygons (a), IDW (b) and areas of influence (c) for SMBR. 
Table 2. GLM final models. Variables which have a higher contribution to the model are expected to exhibit a greater significance (low p-value) and higher value of DAIC. Name codes for variables (see Table 1 for full names) are followed by a letter indicating the interpolation method (I: IDW, T: Thiessen, A: areas of influence).

\begin{tabular}{cccccc}
\hline \multicolumn{3}{c}{ Coyuquilla } & \multicolumn{3}{c}{ SMBR } \\
\hline Variables & p-value & DAIC & Variables & p-value & DAIC \\
\hline MI- I & $0.000605^{\mathrm{a}}$ & 122 & MI-T & $4.41 \mathrm{e}-08^{\mathrm{a}}$ & 29.3 \\
WS-T & $2.0 \mathrm{e}-16^{\mathrm{a}}$ & 34.2 & EF-I & $0.0000641^{\mathrm{a}}$ & 14.9 \\
MI- A & $1.79 \mathrm{e}-08^{\mathrm{a}}$ & 22.5 & WS-I & $0.000247^{\mathrm{a}}$ & 13 \\
EF-I & $2.0 \mathrm{e}-16^{\mathrm{a}}$ & 16.1 & EF-A & $0.000549^{\mathrm{a}}$ & 11 \\
TP-I & $1.38 \mathrm{e}-16^{\mathrm{a}}$ & 15.4 & EF-T & $0.002065^{\mathrm{b}}$ & 8.4 \\
TP-A & $0.000492^{\mathrm{a}}$ & 13.7 & WS-A & $0.002466^{\mathrm{b}}$ & 8 \\
TP-T & $0.344161^{\mathrm{c}}$ & 6.5 & MW-A & $0.005854^{\mathrm{b}}$ & 6 \\
EF-T & $0.005852^{\mathrm{b}}$ & 1.4 & MI-I & $0.014379^{\mathrm{c}}$ & 4.9 \\
WW-I & $2.0 \mathrm{e}-16^{\mathrm{a}}$ & 0.3 & WS-T & $0.033286^{\mathrm{c}}$ & 3.5 \\
\hline
\end{tabular}

Significance levels ${ }^{\mathrm{a}} \mathrm{p}<0.0001,{ }^{\mathrm{b}} \mathrm{p}<0.001,{ }^{\mathrm{c}} \mathrm{p}<0.01$.

the best interpolation technique able to interpolate the socioeconomic variables with more independent contribution for explaining the deforestation process. When comparing the results obtained through the HP and GLM approach, it is possible to note that the latter was not able to offer information in terms of selection of one interpolation technique and just offered a mix of them.

\section{Discussion}

The spatial distribution of the values associated with each location can explain why the Thiessen polygons method interpolated "better" the socioeconomic variables for SMBR than the IDW technique used for Coyuquilla. Figure 5(a) shows how localities with similar values of marginalization index in the SMBR tend to aggregate in space in a clustered pattern (i.e. with high spatial autocorrelation, Moran index $=0.65$ ). In contrast, the values of the neighboring localities in the Coyuquilla have contrasting values without any pattern (low spatial correlation, with Moran index $=-0.01$ ).

\section{Conclusion}

Socioeconomic local data information is a basic input not only for studies about the drivers of deforestation processes, but also for the purpose of its modeling. None of these studies, however, include as a first step an evaluation and selection of the interpolation techniques that are to be used to express the socioeconomic variables. The selection of an appropriate spatial interpolation technique
Table 3. Hierarchical partitioning results with all variables interpolated through the three methods for Coyuquilla and SMBR. Name codes for variables (see Table 1 for full names) are followed by a letter indicating the interpolation method (I: IDW, T: Thiessen, A: areas of influence). The letter I represents the independent contribution, and $J$ is the joint influence in the response variable (deforestation).

\begin{tabular}{|c|c|c|c|}
\hline \multicolumn{4}{|c|}{ Coyuquilla } \\
\hline Variables & I & $\mathrm{J}$ & Total \\
\hline WS-I & 81.986 & 264.427 & 346.413 \\
\hline EF-I & 59.752 & 144.330 & 204.082 \\
\hline MI-I & 53.302 & 104.696 & 157.999 \\
\hline PT-I & 50.077 & 129.792 & 179.869 \\
\hline WW-I & 42.819 & 181.812 & 224.632 \\
\hline WS-T & 38.844 & 96.584 & 135.429 \\
\hline WW-A & 32.067 & 68.776 & 100.843 \\
\hline WW-T & 31.966 & 64.07 & 96.037 \\
\hline TP-T & 29.212 & 49.84 & 79.057 \\
\hline EF-A & 15.917 & -7.620 & 8.296 \\
\hline MI-T & 15.072 & -12.906 & 2.165 \\
\hline MI-A & 15.059 & -9.342 & 5.717 \\
\hline \multicolumn{4}{|c|}{ SMBR } \\
\hline Variables & I & $\mathrm{J}$ & Total \\
\hline MI-T & 12.497 & 52.397 & 64.893 \\
\hline IM-A & 8.712 & 43.468 & 52.179 \\
\hline MW-T & 7.237 & 27.149 & 34.386 \\
\hline EF-T & 7.187 & 34.784 & 41.971 \\
\hline WS-I & 7.065 & 32.770 & 39.834 \\
\hline EF-A & 6.428 & 34.352 & 40.780 \\
\hline MW-A & 5.886 & 25.049 & 30.935 \\
\hline WS-T & 5.780 & 30.707 & 36.487 \\
\hline WS-A & 4.515 & 20.793 & 25.308 \\
\hline MI-I & 4.036 & 14.476 & 18.512 \\
\hline EF-I & 3.716 & 9.072 & 12.788 \\
\hline MW-I & 2.179 & -0.490 & 1.689 \\
\hline
\end{tabular}

for the data at hand is critical, but it is not an easy task, since a technique is "best" only for specific situations [27]. According to the results presented here, the HP statistical approach provides a way not only to select the most suitable interpolation technique, but also to estimate the quantitative contribution of each socioeconomic variable 


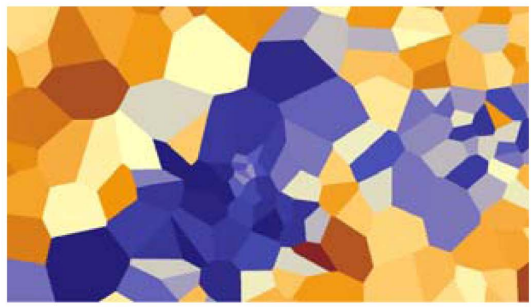

(a)

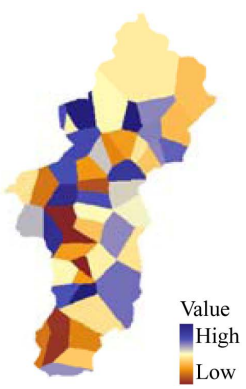

(b)
Figure 5. Comparison of marginalization index values interpolated with the Thiessen polygons method for the SMBR (a) and Coyuquilla (b).

in the deforestation process by avoiding colinearity problems. This information, combined with spatial autocorrelation analysis based on both feature location and feature value, permits to understand how the data's spatial distribution is a determining factor in the selection of the interpolator.

\section{Acknowledgements}

This research was supported by the Consejo Nacional de Ciencia y Tecnología (CONACYT) through grants for the Geography and Biological Sciences graduate programs at UNAM and the project PAPIIT IN113511.

\section{REFERENCES}

[1] P. M. Vitousek, "Beyond Global Warming: Ecology and Global Change," Ecology, Vol. 75, No. 7, 1994, pp. 18611876. doi:10.2307/1941591

[2] C. Agarwal, G. M.Green, J. M. Grove, T. P. Evans and C. M. Schweik, "A Review and Assessment of Land-Use Change Models: Dynamics of Space, Time, and Human Choice," CIPEC Collaborative Report No.1, Department of Agriculture, Forest Service, Northeastern Research Station, Newton Square, 2002, p. 61. doi:10.1016/S1364-8152(03)00161-0

[3] J. F. Mas, H. Puig, J. L. Palacio and A. S. Lopez, "Modelling Deforestation Using GIS and Artificial Neural Networks," Environment Modelling and Software, Vol. 19, No. 5, 2004, pp. 461-471.

[4] FAO, "Global Forest Resources Assessment 2005: Progress towards Sustainable Forest Management," FAO Forestry Paper 147, Food and Agriculture Organization of the United Nations, Rome, 2006.

[5] J. C. Allen and D. F. Barnes, "The Causes of Deforestation in Developing Countries," Annals of the Association of American Geographers, Vol. 75, No. 2, 1985, pp. 163184. doi:10.1111/j.1467-8306.1985.tb00079.x

[6] A. Angelsen and D. Kaimowitz, "Rethinking the Causes of Deforestation: Lessons from Economic Models," World Bank Research Observer, Vol. 14, No. 1, 1999, pp. 73-98. doi:10.1093/wbro/14.1.73
[7] H. J. Geist and E. F. Lambin, "What Drives Tropical Deforestation? A Meta-Analysis of Proximate and Underlying Causes of Deforestation Based on Subnational Scale Case Study Evidence," LUCC Report Series, No. 4, University of Louvain, Louvainla-Neuve, 2001.

[8] E. F. Lambin, B. L. Turner, J. G. Helmut, et al., "The Causes of Land-Use and Land-Cover Change: Moving beyond the Myths," Global Environmental Change, Vol. 11, No. 4, 2001, pp. 261-269. doi:10.1016/S0959-3780(01)00007-3

[9] M. Voltz and R. Webster, "A Comparison of Kriging, Cubic Splines and Classification for Predicting Soil Properties from Sample Information," Journal of Soil Science, Vol. 41, No. 3, 1990, pp. 473-490. doi:10.1111/j.1365-2389.1990.tb00080.x

[10] P. I. Booker, "Modeling Spatial Variability Using Soil Profiles in the Riverland of South Australia," Environment International, Vol. 27, No. 2, 2001, pp. 121-126. doi:10.1016/S0160-4120(01)00071-X

[11] I. A. Nalder and R. Wein, "Spatial Interpolation of Climatic Normals: Test of a New Method in the Canadian Boreal Forest," Agricultural and Forest Meteorology, Vol. 91, No. 4, 1998, pp. 211-225. doi:10.1016/S0168-1923(98)00102-6

[12] J. Wallerman, S. Joyce, C. P. Vencatasawmy and H. Olsson, "Prediction of Forest Steam Volume Using Kriging Adapted to Detect Edges," Canadian Journal Forest Research, Vol. 32, No. 3, 2002, pp. 509-518. doi:10.1139/x01-214

[13] J. L. Hernandez-Stefanoni and R. Ponce-Hernandez, "Mapping the Spatial Variability of Plant Diversity in a Tropical Forest: Comparison of Spatial Interpolation Methods," Environmental Monitoring and Assessment, Vol. 1, No. 117, 2006, pp. 307-334. doi:10.1007/s10661-006-0885-Z

[14] FAO, "Forest Resources Assesment 1990. Survey of Tropical Forest Cover and Study of Change Process," No. 130, Food and Agriculture Organization of the United Nations, Rome, 1996.

[15] F. Achard, H. D. Eva, H. J. Stibin, P. Mayaux, J. Gallego, T. Richards and J. P. Malingreau, "Determination of Deforestation Rates of the World's Humid Tropical Forests," Science, Vol. 297, No. 5583, 2002, pp. 999-1002. doi:10.1126/science. 1070656

[16] R Development Core Team, "R: A Language and Environment for Statistical Computing. R Foundation for Statistical Computing," Vienna, 2011. http://www.R-project.org

[17] P. A. Burrough and R. A. MacDonell, "Principles of Geographical Information Systems (Spatial Information Systems and Geostatistics)," Oxford University Press, Oxford, 1998

[18] J. Li and A. D. Heap, "A Review of Comparative Studies of Spatial Interpolation Methods in Environmental Sciences: Performance and Impact Factors," Ecological Informatics, Vol. 6, No. 6, 2011, pp. 228-241. doi:10.1016/j.ecoinf.2010.12.003

[19] K. P. Burnham and D. R. Anderson, "Model Selection 
and Multimodel Inference," Springer-Verlag, New York, 2002.

[20] R. Mac Nally, "Regression and Model Building in Conservation Biology, Biogeography and Ecology: The Distinction between and Reconciliation of 'Predictive' and 'Explanatory' Models," Biodiversity and Conservation, Vol. 9, No. 5, 2000, pp. 655-671. doi:10.1023/A:1008985925162

[21] R. Mac Nally, "Hierarchical Partitioning as an Interpretative Tool in Multivariate Inference," Australian Journal of Ecology, Vol. 21, No. 2, 1996, pp. 224-228. doi:10.1111/j.1442-9993.1996.tb00602.x

[22] A. Chevan and M. Sutherland, "Hierarchical Partitioning," The American Statistician, Vol. 45, No. 2, 1991, pp. 90-96.

[23] R. Mac Nally and C. J. Walsh, "Hierarchical Partitioning Public-Domain Software," Biodiversity and Conservation, Vol. 13, No. 3, 2004, pp. 659-660.
doi:10.1023/B:BIOC.0000009515.11717.0b

[24] R. Mac Nally, "Multiple Regression and Inference in Ecology and Conservation Biology: Further Comments on Identifying Important Predictor Variables," Biodiversity and Conservation, Vol. 11, No. 8, 2002, pp. 13971401. doi:10.1023/A:1016250716679

[25] S. T. Buckland, K. P. Burnham and N. H. Augustin, "Model Selection: An Integral Part of Inference," Biometrics, Vol. 53, No. 2, 2002, pp. 603-618. doi:10.2307/2533961

[26] M. Baumann, T. Kuemmerle, M. Elbakidze, M. Ozdogan, V. C. Radeloff, N. S. Keuler, A. V. Prishchepov, I. Kruhlov and P. Hostert, "Patterns and Drivers of PostSocialist Farmland Abandonment in Western Ukraine," Land Use Policy, Vol. 28, No. 3, 2011, pp. 552-562. doi:10.1016/j.landusepol.2010.11.003

[27] E. H. Isaaks and R. M. Srivastava, "Applied Geostatistics," Oxford University Press, New York, 1989. 